\title{
AVALIAÇÃO DA PRESENÇA DE MIOFIBROBLASTOS NO ESTROMA DE CARCINOMAS ESPINOCELULAR ORAIS EM PACIENTES JOVENS
}

\author{
Marina Barbosa Azevedo (IC), Felipe Paiva Fonseca, Ricardo Della Colleta, Ana Carolina Prado Ribeiro, Ana Maria Pires Soubia, \\ Glauco Issamu Miyahara, Roman Carlos, Paula Farthing, Keith D. Hunter, Paul M. Speight, Pablo Augustin Varhas, Marcio Ajudarte \\ Lopes, Alan Roger dos Santos Silva
}

\section{Resumo}

O aumento do número de pacientes jovens com carcinoma espinocelular vem estimulando vários estudos. Entretanto, nenhum estudo foi realizado afim de testar a hipótese de uma associação entre a presença e função dos miofibroblastos no estroma tumoral de jovens e o diferente comportamento biológico desses tumores, comparando com mesmo tipo de lesão em pacientes mais velhos. Como resultado não foi observada diferença significativa na comparação entre os grupos e não houve correlação entre a expressão de a-AML no estroma tumoral, grau histológico dos tumores, estágio clínico da doença no momento do diagnóstico ou estado da ploidia tumor.

Palavras Chave: câncer oral, carcinoma espinocelular, miofibroblastos.

\section{Introdução}

A incidência de carcinoma espinocelular em jovens tem mostrado um aumento em diferentes partes do mundo, porém pouco se sabe sobre os exatos mecanismos e os possíveis fatores etiológicos deste carcinoma em pacientes jovens. A associação entre miofibroblastos e CECs bucais de jovens nunca foi investigada. $O$ objetivo deste estudo foi avaliar a presença de miofibroblastos no estroma de CEOs de pacientes jovens e testar a hipótese nula de que o estroma encontrado nesses pacientes é diferente do observado em pacientes mais velhos. A amostra utilizada provém de quatro centros diferentes de Patologia - FOP-Unicamp, UNESP-FOA, Universidade de Shiffield- Inglaterra e Centro Clinico de Cabeza y Cyello -Guatemala-, visando comparar o conteúdo estromal de 29 casos de CEC de língua em jovens com 29 casos de CEC em de língua em pacientes com mais de 40 anos.

\section{Resultados e Discussão}

Os resultados mostraram que $56,8 \%$ dos casos em jovens apresentaram miofibroblastos estromais enquanto que na amostra dos idosos observou-se miofibroblastos estromais em 75,9\% dos tumores. Não foi identificada relação significativa entre miofibroblastos estromais, estadiamento clínico dos tumores e conteúdo de DNA celular entre os grupos. Não houve diferença significativa no componente estromal miofibroblástico de CEC de língua afetando jovens e idosos

\section{Conclusões}

Conclui-se que embora sejam necessários mais estudos para compreender melhor as características biológicas do CEO afetando pacientes jovens, os resultados obtidos sugerem que não houve diferença significativa entre o componente estromal miofibroblástico de CEOs afetando indivíduos jovens e idosos e que miofibroblastos não são os responsáveis por qualquer comportamento clínico diferente nos CEOs de pacientes jovens.

\section{Agradecimentos}

Agradeço ao meu orientador Alan Roger dos Santos Silva pela paciência com que conduziu a orientação desse trabalho e ao CNPq pela oportunidade de a pesquisa ser realizada e pelo financiamento da bolsa. 